\title{
Evaluation of endometrium by transvaginal ultrasonography and hysteroscopy and its correlation with histopathology in perimenopausal women with abnormal uterine bleeding at tertiary rural centre
}

\author{
Priyanka Singh $^{1 *}$, Kalpana Kumari ${ }^{1}$, Shikha Seth ${ }^{1}$, Vandana Verma ${ }^{1}$, Vikram Singh ${ }^{2}$
}

\author{
${ }^{1}$ Department of Obstetrics and Gynecology, Uttar Pradesh University of Medical Sciences, Saifai, Etawah, Uttar \\ Pradesh, India \\ ${ }^{2}$ Department of Surgery, Uttar Pradesh University of Medical Sciences, Saifai Etawah, Uttar Pradesh, India
}

Received: 03 December 2019

Accepted: 02 January 2020

\author{
*Correspondence: \\ Dr. Priyanka Singh, \\ E-mail: vivansingh1811@gmail.com
}

Copyright: () the author(s), publisher and licensee Medip Academy. This is an open-access article distributed under the terms of the Creative Commons Attribution Non-Commercial License, which permits unrestricted non-commercial use, distribution, and reproduction in any medium, provided the original work is properly cited.

\begin{abstract}
Background: Abnormal uterine bleeding is one of the commonest clinical presentation ac-counts for $33 \%$ gynaecological consultations and this proportion rises to $70 \%$ in perimenopausal and postmenopausal age group in any gynaecology clinic. The most probable etiology of abnormal uterine bleeding relates to the patients reproductive age. Various diagnostic techniques have been evolved over the periods to determine the etiology of abnormal uterine bleeding in perimenopausal women, but their accuracy has not been compared properly. The aim of study is to evaluate the endometrium by transvaginal ultrasonography and hysteroscopy and its correlation with histopathology in perimenopausal patients with abnormal uterine bleeding.

Methods: Total 96 patients in perimenopausal age group, admitted with chief complaints of ab-normal uterine bleeding were included. All patients underwent transvaginal ultrasonography and hysteroscopy, followed by hysteroscopy guided biopsy and histopathological examination. Accuracy, sensitivity, specificity, positive predictive value and negative predictive value were calculated for both methods and compared, considering histopathological diagnosis as gold standard.

Results: Mean age of patients was 44.05 \pm 3.29 . Hysteroscopy has high accuracy, sensitivity, specificity, positive predictive value and negative predictive value than Transvaginal sonography for diagnosis of all endometrial and intrauterine pathologies.

Conclusions: Hysteroscopy results are more consistent with the results of histopathology. Hysteroscopy and hysteroscopy guided biopsy has been proven as gold standard for endometrial evaluation of patients with abnormal uterine bleeding. TVS can be used as most cost effective first step investigation in cases of perimenopausal bleeding.
\end{abstract}

Keywords: Abnormal uterine bleeding, Histopathology, Hysteroscopy, Transvaginal ultrasonography, perimenopausal women

\section{INTRODUCTION}

Abnormal uterine bleeding is defined as bleeding from the uterine corpus that is abnormal in regularity, volume, frequency or duration and occurs in the absence of pregnancy. ${ }^{1}$ Abnormal uterine bleeding is one of the commonest clinical presentation accounts for $33 \%$ gynaecological consultations and this proportion rises to $70 \%$ in perimenopausal and postmenopausal age group. ${ }^{2}$

Abnormal uterine bleeding in perimenopausal age group is common but ill-defined entity. Peri-menopause is 
defined as the period beginning with menopausal transition and ending 12 months after the last menstrual period. ${ }^{3}$ The varied pattern of endometrial changes, symptomatic presentation and more incidence of abnormal uterine bleeding in perimenopausal women makes accurate and prompt diagnosis essential for appropriate management. This has attracted our attention in perimenopausal women and challenged us to undertake this study.

The International Federation of Gynaecology and Obstetrics (FIGO) in November 2010 developed a standardised classification system (PALM-COEIN) for causes of the abnormal uterine bleeding. ${ }^{4}$

PALM include structural causes and COEIN include nonstructural causes of AUB.

To evaluate the endometrium as a cause of AUB in perimenopausal age group presently we have three modalities ${ }^{5}$ :

- Imaging pattern of endometrium by transvaginal sonography (TVS)

- Visual assessment by hysteroscopy

- Cellular assessment by microscopic evaluation of endometrium samples.

Transvaginal sonography is an inexpensive, non-invasive, quick, painless, and a convenient way to indirectly visualize the intrauterine abnormalities in abnormal uterine bleeding women. In addition, it can also help to visualise the myometrium, endomyometrial junction, bilateral adnexa and ovaries. The endometrium should be measured in the long axis or sagittal plane.

We used $12 \mathrm{~mm}$ thickness of endometrium as the upper limit of normal in perimenopausal patients, beyond which it was called thickened endometrium. Thickened endometrium on transvaginal sonography is expected to correlate with endometrial hyperplasia on histopathology or hyperplastic/polypoidal endometrium on hysteroscopy. TVS is recommended as first line and minimal invasive diagnostic tool for assessing uterine pathology in abnormal uterine bleeding. ${ }^{6}$ Hysteroscopy is the endoscopic evaluation of endometrial cavity via a telescope inserted through cervix. There are multiple and widespread applications for hysteroscopy, as it allows for direct visualisation and diagnosis of intrauterine abnormalities and it often offers an opportunity for simultaneous treatment. ${ }^{7}$ It can be performed in an office setting (outpatient hysteroscopy) or as a day care procedure under anaesthesia (inpatient hysteroscopy). The endometrial biopsy involves taking a tissue sample of the endometrial lining of the uterus. The tissue subsequently undergoes a histological evaluation.

Hysteroscopically directed sampling detect a higher percentage of abnormalities. Even if the uterine cavity appears normal at hysteroscopy, the endometrium should be sampled since hysteroscopy alone is not sufficient to exclude endometrial neoplasia and carcinoma. ${ }^{8}$ In the present study, hysteroscopy guided biopsy is performed for cellular assessment of endometrial tissue.

The primed responsibility of a gynecologist is to rule out the presence of endometrial malignancy in cases of AUB, especially in women of perimenopausal and menopausal age group. The aim of our study is to evaluate the endometrium by transvaginal ultrasonography and hysteroscopy and its cor-relation with histopathology in perimenopausal patients with abnormal uterine bleeding.

\section{METHODS}

This was a hospital based prospective comparative observational study conducted on 96 peri-menopausal female patients between 40 to 50 years with abnormal uterine bleeding admitted in department of obstetrics and gynaecology in collaboration with department of pathology at Uttar Pradesh University of Medical Sciences, Saifai, Etawah from January 2017 to June 2018.

Perimenopausal women of age 40-50 years but not achieved clinical menopause (not yet gone for 12 consecutive months of amenorrhea with abnormal uterine bleeding) were included in the study. Women of age group less than 40 years and more than 50 years, postmenopausal women, pregnancy and related causes of bleeding per vagina, women with intrauterine contraceptive device, women with coagulation disorders, women with known genital tract malignancy, women on hormonal therapy, women with cervicitis and vaginitis, women with recent uterine perforation, chronic medical illness including endocrine disorders, hemodynamically unstable patients, uterus size larger than 12 weeks gestation, women on medications like neuroleptics, anticoagulants and cytotoxic agents were excluded from the study. After obtaining written informed consent, each patient underwent a preliminary assessment by de-tailed history and clinical examination. All cases were subjected to transvaginal sonography, hysteroscopy and histopathology examination of endometrial sampling for evaluation of intrauterine pathology. Data were collected on a data collection sheet.

The patient was first evaluated with the transvaginal sonography. Transvaginal sonography was done using a 3-7 $\mathrm{MHz}$ endovaginal transducer. The uterus was evaluated in both the transverse and sagittal planes. Irregularities, thickness, echo pattern of endometrium and myometrium inter phase in the long axis and transverse plane were noted. Two-layer thickness of endometrium in anteroposterior dimension was taken in sagittal section view. Endometrial thickness of less than 12 was not-ed as normal endometrium and more than $12 \mathrm{~mm}$ was noted as thickened endometrium. Uterine pathology, adnexal and any other pelvic pathology was noted. 
After transvaginal ultrasonography and pre-anesthetic checkup, patient was posted for hysteroscopy. Hysteroscopy was done with a rigid hysteroscope consisting of a telescope with a $3.7 \mathrm{~mm}$ outer diameter and a foroblique vision of $30^{\circ}$. Normal saline was used as distension media. Systematic examination of all four walls of the uterine cavity, fundus and the tubal openings was carried out.

The following observations were recorded on hysteroscopic examination: Panoramic view of uterine cavity for presence of endometrial polyp, leiomyoma, hyperplasia, carcinoma, any endometrial synechiae and foreign body, endometrium appearance, thickness and colour, tubal ostia and bilateral cornua, endocervical canal for any growth and polyp and Any other abnormalities. Hysteroscopic findings were noted on the patient's case sheet. The endometrial specimens were received using uterine curette just after hysteroscopy (hysteroscopy guided biopsy) from all the walls of uterus, including fundus or from suspicious wall in case of focal lesions. Specimen is collected in $10 \%$ formalin solution and sent for histopathological examination.

\section{Statistical analysis}

For data analysis, qualitative variables were compared using Chi-Square test /Fisher's exact test as appropriate. To assess the validity between TVS and hysteroscopy, accuracy, sensitivity, specificity, PPV (positive predictive value) and NPV (negative predictive value) are used.

\section{RESULTS}

As per the current study data on 96 cases as a sample, following observations and results were made out.

Out of 96 cases, $66.70 \%$ of women were in the age group of $40-45$ years and $35.41 \%$ women in $45-50$ years. Mean age of patients is $44.05 \pm 3.29$ (Table 1 ).

Table 1: Distribution of cases according to age.

\begin{tabular}{|lll|}
\hline Age interval & Number of cases & Percentage \\
\hline $40-45$ years & 64 & $66.7 \%$ \\
\hline $45-50$ years & 32 & $33.3 \%$ \\
\hline Total & $\mathbf{9 6}$ & $\mathbf{1 0 0 . 0 \%}$ \\
\hline Mean \pm SD deviation & & $44.05 \pm 3.29$ \\
\hline
\end{tabular}

Table 2: Distribution of cases according to socioeconomic status.

\begin{tabular}{|lll|}
\hline Socioeconomic status & Number of cases & Percentage \\
\hline Upper & 2 & $2.1 \%$ \\
\hline Upper middle & 24 & $25.0 \%$ \\
\hline Lower middle & 41 & $42.7 \%$ \\
\hline Upper lower & 20 & $20.8 \%$ \\
\hline Lower & 9 & $9.4 \%$ \\
\hline Total & $\mathbf{9 6}$ & $\mathbf{1 0 0 . 0 \%}$ \\
\hline
\end{tabular}

The cases in our study consisted of $42.7 \%$ of patients from lower middle class and $30 \%$ cases below this class indicating predominance of lower socioeconomic status patients with abnormal uterine bleeding. Only $2.1 \%$ cases were from upper class (Table 2). On transvaginal sonography, normal endometrium (ET less than $12 \mathrm{~mm}$ ) was found in $56.2 \%$ cases (Table 3). Most common abnormal finding was thickened endometrium (ET more than $12 \mathrm{~mm}$ ) i.e. suspected hyperplasia.

\section{Table 3: Distribution of cases according to transvaginal sonography finding.}

\begin{tabular}{|lll|}
\hline TVS findings & $\begin{array}{c}\text { Number } \\
\text { of cases }\end{array}$ & Percentage \\
\hline Normal endometrium & 54 & $56.2 \%$ \\
\hline (ET<12 mm) & & \\
\hline Thickened endometrium & 29 & $30.2 \%$ \\
\hline$($ ET $>12 \mathrm{~mm})$ & & \\
\hline Endometrial polyp & 8 & $8.3 \%$ \\
\hline Submucous myoma & 5 & $5.2 \%$ \\
\hline Total & $\mathbf{9 6}$ & $\mathbf{1 0 0 \%}$ \\
\hline
\end{tabular}

On hysteroscopy, normal endometrium were seen in $43.8 \%$ of cases- proliferative $28(29.2 \%)$ and secretory 14 (14.6\%) cases. Most common abnormal finding was hyperplastic endometrium (22.9\%), followed by endometrial polyp (20.8\%), submucous myoma $(8.3 \%)$, endometritis $(3.1 \%)$ and carcinoma endometrium (1.04\%) (Table 4).

Table 4: Distribution of cases according to hysteroscopy finding.

\begin{tabular}{|lll|}
\hline Hysteroscopy finding & $\begin{array}{l}\text { Number } \\
\text { of cases }\end{array}$ & Percentage \\
\hline Proliferative endometrium & 28 & $29.2 \%$ \\
\hline Secretory endometrium & 14 & $14.6 \%$ \\
\hline Endometrial polyp & 20 & $20.8 \%$ \\
\hline Submucous myoma & 8 & $8.3 \%$ \\
\hline Hyperplastic endometrium & 22 & $22.9 \%$ \\
\hline Endometritis & 3 & $3.1 \%$ \\
\hline Carcinoma endometrium & 1 & $1.0 \%$ \\
\hline Total & $\mathbf{9 6}$ & $\mathbf{1 0 0 . 0 \%}$ \\
\hline
\end{tabular}

Table 5: Distribution of cases according to histopathology finding.

\begin{tabular}{|lll|}
\hline Histopathological finding & $\begin{array}{l}\text { Number } \\
\text { of cases }\end{array}$ & Percentage \\
\hline Proliferative endometrium & 20 & $20.8 \%$ \\
\hline Secretory endometrium & 16 & $16.7 \%$ \\
\hline Endometrial polyp & 14 & $14.6 \%$ \\
\hline Submucous myoma & 8 & $8.3 \%$ \\
\hline Hyperplastic endometrium & 29 & $30.2 \%$ \\
\hline Endometritis & 8 & $8.3 \%$ \\
\hline Carcinoma endometrium & 1 & $1.04 \%$ \\
\hline Total & $\mathbf{9 6}$ & $\mathbf{1 0 0 . 0 \%}$ \\
\hline
\end{tabular}


Out of 96 cases, the maximum number of cases had normal endometrium including proliferative $(20.8 \%)$ and secretory $(16.7 \%)$ and rest had abnormal endometrium, most common of which was hyperplastic endometrium
(30.2\%). Others are endometrial polyp (14.6\%), submucous myoma (8.3\%), endometritis (8.3\%) and carcinoma endometrium (1.04\%) (Table 5).

Table 6: Diagnostic characteristics of TVS for causes of AUB in perimenopausal women.

\begin{tabular}{|llllll|} 
& Accuracy & Sensitivity & Specificity & PPV & NPV \\
\hline Normal endometrium & $50.94 \%$ & $51.16 \%$ & $50.00 \%$ & $81.48 \%$ & $19.23 \%$ \\
\hline Endometrial polyp & $19.81 \%$ & $9.30 \%$ & $65.00 \%$ & $53.33 \%$ & $14.29 \%$ \\
\hline Thickened endometrium & $45.28 \%$ & $33.72 \%$ & $95.00 \%$ & $96.67 \%$ & $25.00 \%$ \\
\hline Submucous myoma & $21.69 \%$ & $5.8 \%$ & $90.00 \%$ & $71.43 \%$ & $18.18 \%$ \\
\hline
\end{tabular}

Table 7: Diagnostic characteristics of hysteroscopy for causes of AUB in perimenopausal women.

\begin{tabular}{|llllll|}
\hline & Accuracy & Sensitivity & Specificity & PPV & NPV \\
\hline Proliferative endometrium & $85.41 \%$ & $60.71 \%$ & $95.59 \%$ & $85.00 \%$ & $85.53 \%$ \\
\hline Secretory endometrium & $95.83 \%$ & $92.86 \%$ & $96.34 \%$ & $81.25 \%$ & $98.75 \%$ \\
\hline Endometrial polyp & $91.67 \%$ & $65.00 \%$ & $83.33 \%$ & $92.86 \%$ & $41.67 \%$ \\
\hline Submucous myoma & $100.00 \%$ & $100.00 \%$ & $100.00 \%$ & $100.00 \%$ & $100.00 \%$ \\
\hline Hyperplastic endometrium & $86.46 \%$ & $86.36 \%$ & $86.49 \%$ & $65.52 \%$ & $95.52 \%$ \\
\hline Endometritis & $94.79 \%$ & $100.00 \%$ & $94.62 \%$ & $37.50 \%$ & $100.00 \%$ \\
\hline Carcinoma endometrium & $100.00 \%$ & $100.00 \%$ & $100.00 \%$ & $100.00 \%$ & $100.00 \%$ \\
\hline
\end{tabular}

Accuracy, sensitivity, specificity and negative predictive value of Transvaginal sonography for most of the endometrial condition is quiet poor, however positive predictive value is good except for endometrial polyp, suggesting it has less diagnostic efficacy for endometrial polyp (Table 6).

Hysteroscopy shows high accuracy, sensitivity, specificity, PPV and NPV for almost all the endometrial conditions (Table 7).

\section{DISCUSSION}

Abnormal uterine bleeding in perimenopausal women have varied aetiologies ranging from physio-logical hormonal changes on one hand to endometrial neoplastic changes either benign or malignant, on the other hand. The mean age of patients in our study was 44.05 \pm 3.29 years. Lotha et al, Talukdar et al, Katke et al, and Pillai et al results were similar to this studies. ${ }^{9-12}$ All the cases enrolled in our study are stratified according to modified Kuppuswamy scale. Since this hospital covers most of rural population, maximum number of cases are in lower middle class- $41(42.7 \%)$.

On transvaginal sonography we observe $56.2 \%$ cases with normal endometrium (ET less than $12 \mathrm{~mm}$ ), 30.2\% cases of thickened endometrium (ET more than $12 \mathrm{~mm}$ ) i.e. suspected hyperplasia, which was the commonest abnormal finding. In the present study we have taken ET more than $12 \mathrm{~mm}$ to suspect hyperplastic endometrium. Various other studies including Malpani et al, Pillai et al, have established correlation between endometrial thickness and the presence of endometrial abnormalities in curettage material. ${ }^{12.13}$

Hysteroscopy provides direct visualization of intrauterine cavity, in fact, it is an eye in the uterus. On hysteroscopy, normal endometrium were seen $44.8 \%$ of cases of which $29.2 \%$ were proliferative and $14.6 \%$ were secretory. This was comparable to Singh et al and Patil et al who observed $48 \%$ and $50 \%$ cases with normal endometrium. ${ }^{14,15}$ Most common abnormal finding was hyperplastic endometrium $(22.9 \%)$, followed by endometrial polyp (20.8\%), submucous myoma $(8.3 \%)$, endometritis $(3.1 \%)$ and carcinoma endometrium (1.04\%).

On histopathology, the maximum number of cases had normal endometrium including proliferative (20.8\%) and secretory $(16.7 \%)$ and rest had abnormal endometrium, most common of which was hyperplastic endometrium (30.2\%), others are endometrial polyp (14.6\%), submucous myoma (8.3\%), endometritis $(8.3 \%)$ and carcinoma endometrium (1.04\%).

Hysteroscopy shows high accuracy, sensitivity, specificity, PPV and NPV for almost all the endometrial conditions as compared to transvaginal sonography. Similar results were reported in studies of Katke et al, Jaiswar et al, Dasgupta $\mathrm{S}$ et al, and Bouzari Z et al. ${ }^{11,16-18}$

\section{CONCLUSION}

Hysteroscopy and hysteroscopy guided biopsy has been proven as gold standard for endometrial evaluation of 
patients with abnormal uterine bleeding in perimenopausal age group. Transvaginal sonography should be used as an complementary procedure to hysteroscopy in the work up of patients with abnormal uterine bleeding as it is an inexpensive, non-invasive, quick, painless and convenient procedure.

\section{Funding: No funding sources}

Conflict of interest: None declared

Ethical approval: The study was approved by the Institutional Ethics Committee

\section{REFERENCES}

1. Munro MG, Critchley HO, Broder MS, Fraser IS. The FIGO recommendations on terminologies and definitions for normal and abnormal uterine bleeding. Semin Reprod Med. 2011;29(5):383-90.

2. Mahajan N, Aggarwal M, Bagga A. Health issues of menopausal women in North India. J Midlife Health. 2012;3:84-7.

3. Soules MR, Sherman S, Parrott E, Rebar R, Santoro $\mathrm{N}$, Utian W, et al. Executive summary: stages of reproductive aging workshop (STRAW). Fertil Steril. 2001;76(5):874-8.

4. Goldstein SR, Zeltser I, Horan CK, Snyder JR, Schwartz LB. Ultrasonography based triage for perimenopausal patients with abnormal uterine bleeding. Am J Obstet Gynecol. 1997;177:102-8.

5. Munro MG, Critchley Ho, Broder MS, Eraser IS. FIGO classification system (PALM-CO-EIN) for causes of abnormal uterine bleeding in non-gravid women of reproduction age. FIGO Working Group on Menstrual Disorders. Int J Gynecol Obstet. 2011;113:3-13.

6. Aslam M, Ijaz L, Tariq S Shafqat K. Comparison of transvaginal sonography and saline contrast sonohysterograhy in women with abnormal uterine bleeding: correlation with hysteroscopy and histopathology. Int J Health Sci. 2007;1(1):17-24.

7. Cooper JM, Brady RM. Hysteroscopy in the management of abnormal uterine bleeding. Ob-stet Gynecol Clin North Am. 1999;26(1):217-36.

8. Nagele FO, O'connor H, Davies A, Badawy A, Mohamed H, Magos A. 2500 outpatient diagnostic hysteroscopies. Obstet Gynecol. 1996;88(1):87-92.

9. Lotha L, Borah A. Clinicopathological evaluation of abnormal uterine bleeding in peri-menopausal women. Int J Reprod Contracept Obstet Gynecol. 2016;5(9):3072-74.

10. Talukdar B, Mahela S. Abnormal uterine bleeding in perimenopausal women: Correlation with sonographic findings and histopathological examination of hysterectomy specimens. J Midlife Health. 2016;7(2):73-77.

11. Katke RD, Zarariya AN. Use of diagnostic hysteroscopy in abnormal uterine bleeding in perimenopausal age group and its clinicopathological correlation with ultrasound and histopathology findings: experience in a tertiary care institute. Int $\mathbf{J}$ Reprod Contracept Obstet Gynecol. 2015;4(2):413-8.

12. Pillai SS. Sonographic and histopathological correlation and evaluation of endometrium in perimenopausal women with abnormal uterine bleeding. Int J Reprod Contracept Obstet Gynecol. 2014;3(1):113-17.

13. Malpani A, Singer J, Wolverson MK, Merenda G. Endometrial hyperplasia: value of endometrial thickness in ultrasonographic diagnosis and clinical significance. J Clin Ultrasound. 1990;18:173-7.

14. Singh S, Taneja BK, Singh $P$ et al. Role of diagnostic hysteroscopy in abnormal uterine bleeding. Int $\mathbf{J}$ Reprod Contracept Obstet Gynecol. 2014;3:544-51.

15. Patil SG, Bhute SB, Inamdar SA, Acharya NS, Shrivastav DS. Role of diagnostic hysteroscopy in abnormal uterine bleeding and its histopathological correlation. J Gynecol Endosc Surg. 2009;1(2):98104.

16. Jaiswar SP, Sachan R, Srivastava PK, Goel M, Pande M. A comparative diagnostic evalua-tion of hysteroscopy, transvaginal ultrasonography and histopathological examination in cases of abnormal uterine bleeding. J Obstet Gynecol India. 2006;56(3):240-3.

17. Subhankar D, Chakraborty B, Rejaul K, Kanti AR, Kumar MP, Kumar GT. Abnormal uter-ine bleeding in perimenopausal age: diagnostic options and accuracy. J Obstet Gynecol India. 2011;2(1):189-94.

18. Bouzari Z, Yazdani S, Esmailzadeh S, Shahhoseini R, Fazli A, Naeimi M. Hysteroscopy vs transvaginal ultrasonography in the diagnosis of endometrial lesions. Caspian J Reprod Med. 2016;2(1):21-6.

Cite this article as: Singh $\mathrm{P}$, Kumari $\mathrm{K}$, Seth $\mathrm{S}$, Verma V, Singh V. Evaluation of endometrium by transvaginal ultrasonography and hysteroscopy and its correlation with histopathology in perimenopausal women with abnormal uterine bleeding at tertiary rural centre. Int J Reprod Contracept Obstet Gynecol 2020;9:735-9. 